\title{
Determination of total free amino acids in Sipunculus nudus by UV spectrophotometry
}

\author{
Hongli YE ${ }^{1,2}$, Youqiong CAI ${ }^{1,2}$, Longfei ZHANG ${ }^{3}$, Wei $\mathrm{YU}^{3}$, Yongfu SHI ${ }^{1,2}{ }^{*}$, Liangliang TIAN ${ }^{1,2^{*}}$ \\ ${ }^{1}$ Laboratory of Aquatic Product Quality, Safety and Processing, East China Sea Fisheries Research Institute, Chinese Academy of \\ Fishery Sciences, Shanghai, 200090, China \\ ${ }^{2}$ Key Laboratory of Control of Safety and Quality for Aquatic Product, Ministry of Agriculture and Rural Affairs, Beijing, 100141, \\ China \\ ${ }^{3}$ College of Food Science, Shanghai Ocean University, Shanghai, 201306, China
}

\begin{abstract}
Here we developed a new, facile method to detect free amino acids (TFAA) in Sipunculus nudus by UV spectrophotometry. The pretreatment conditions of the approach were optimized, such as chromogenic reaction temperature and time, the measurement time after chromogenic reaction, the extraction agent and its concentration, the extraction time. The established method showed a good linearity in the TFAA range $0.0 \sim 40.0 \mu \mathrm{g} / \mathrm{mL}\left(\mathrm{R}^{2}=0.9958\right)$ with the limit of detection (LOD) $1.96 \mu \mathrm{g} / \mathrm{mL}$ and the precision of $6.14 \%$ (relative standard deviation, RSD). The addition standard recoveries were $95.1 \%$ $108.6 \%$. Finally, the method was successfully applied in detection of TFAA in Sipunculus nudus and other aquatic products. The results showed that the content of TFAA in Sipunculus nudus was higher than that in the other aquatic products collected in our paper, and as high as $138.14 \mathrm{~g} / \mathrm{kg}$.
\end{abstract}

\section{Introduction}

Sipunculus nudus (S. nudus), as well as also called grid siphon worm and light naked siphon worm, are an important economic and ecological species and widely distributed in the South China Sea region [1-2]. As one of famous marine products, $S$. nudus possess the high nutritional composition, such as protein, mineral elements such as sodium and potassium, water-soluble and fat-soluble vitamins (i.e.VB1, VB2, and VB4), taurine, as well as essential amino acids for human body [3-5]. Furthermore, S. nudus feature the good medicinal values, including the effects of anti-fatigue and antiaging, improving the body immunity and so on [6-9]. Up to now, it has been paid more attention to the exploitation and utilization of $S$. nudus [10-12] especially the amino acids and other nutritional components [5,13]. Amino acids are the essential substances in body, which is responsible for taste and significant correlation with disease prevention, aid to relaxation, blood pressure lowing, and antitumor activity enhancement [14-16].

A variety of detection methods of free amino acids (FAA) have been extensively developed with automatic amino acid analyser [17-20], high performance liquid chromatography (HPLC) [21-23], high performance liquid chromatography-tandem mass spectrometry (HPLC-MS) [24]. However, these methods are frequently time-consuming, requiring special instruments and professional technicians. Consequently, a fast, efficient and capable of analytical approach urgently required to quantify the total amino acids in $S$. nudus for both research and practical applications. Owing to facile operation, good stability, high sensitivity, Ultraviolet and visible spectrophotometry (UV) technology has gained grave attention to the researchers and widely applied in different fields, especially to assess the quality of food products [25-28].

Herein we presented an available method for the detection of TFAA in S. nudus and other aquatic products by UV spectrometry. The established method showed a good linearity in the TFAA range $0.0 \sim 40.0$ $\mu \mathrm{g} / \mathrm{mL}\left(\mathrm{R}^{2}=0.9958\right)$ with the limit of detection (LOD) $1.96 \mu \mathrm{g} / \mathrm{mL}$ and the precision of $6.14 \%$ (relative standard deviation, RSD). The addition standard recoveries were $95.1 \% \sim 108.6 \%$. Finally, it was successfully applied in the detection of the TFAA in $S$. nudus and other aquatic products.

\section{Materials and methods}

\subsection{Sample collection}

The aquatic products mainly involved fresh samples and dried products, for instance Sipunculus nudus, freshwater shrimps, Penaeus monodon, Procambarus clarkii, Eriocheir sinensis, Portunus trituberculatus, Sinonovacula constricta, Macrobranchium nipponense, Paphia undulata, Fried metapenaeusensis, Fried Penaeus vannamei, Venerupis variegata, Roast Loligo chinensis, Roast Cololabis saira, Roast Carassius

* Corresponding author: xyzmn530@sina.com; tian-19860120@163.com 
aumtus, Roast Ophiocephalus argus, Cyprinus carpio, Ophiocephalus argus, Parabramis pekinensis, Carassius aumtus, Lateolabrax japonicus, Pseudosciaena crocea, Siniperca chuatsi, Ostrea rivularis. All the fresh samples were transported back to the laboratory in the car refrigerators, thawed, and homogenized, and kept the fresh samples in the $-20{ }^{\circ} \mathrm{C}$ freezer for refrigeration for further using. The $S$. nudus samples were dried in the oven at $80^{\circ} \mathrm{C}$ for $4 \mathrm{~h}$, and then crushed for further application.

\subsection{Instrument.}

UV spectrophotometer (UV-4100) and high speed centrifuge (CF16RX ॥) were purchased from HITACHI company. Digital display water bath constant temperature oscillator (SG-8016C) was from Shanghai Shuoguo Electronic Technology Co., Ltd. Vortex oscillators were purchased from IKA.

\subsection{Reagent.}

The standard solid powder of glutamic acid $\left(\mathrm{C}_{5} \mathrm{H}_{9} \mathrm{NO}_{4}\right.$, $\geqslant 99 \%$, Glu) was charged from Bei jing Solarbio Life Sciences Company. Ninhydrin $\left(\mathrm{C}_{9} \mathrm{H}_{6} \mathrm{O}_{4}, \geqslant 99 \%\right)$, stannous chloride $\left(\mathrm{SnCl}_{2} \cdot 2 \mathrm{H}_{2} \mathrm{O}\right)$, potassium dihydrogen phosphate $\left(\mathrm{KH}_{2} \mathrm{PO}_{4}\right)$, anhydrous disodium hydrogen phosphate $\left(\mathrm{Na}_{2} \mathrm{HPO}_{4}\right)$, trichloroacetic acid (TCA), sodium hydroxide $(\mathrm{NaOH})$, were all purchased from Sinopharma Chemical Reagent Co. Ltd. Ultrapure water was $18.2 \mathrm{M} \Omega \cdot \mathrm{cm}$. All reagents were analytical degrade without special instructions.

\subsection{The Sample pretreatment.}

Fresh sample. $5 \mathrm{~g}( \pm 0.01 \mathrm{~g})$ of homogenized samples were accurately weighed into the centrifuge tubes with the volume of $50 \mathrm{~mL}$, and $20 \mathrm{~mL}$ of $10 \%$ (wt \%) TCA solution was successively added into the tubes. The samples were shaken vigorously on the vortex oscillators, extracted for $2 \mathrm{~h}$ at room temperature, centrifuged at $10000 \mathrm{r} / \mathrm{min}$ for $5 \mathrm{~min}$. The supernatant was transferred into $25 \mathrm{~mL}$ of colorimetric tubes. Fixed the volume to scale using $10 \%$ (wt \%) TCA solution and mixed the system adequately, $5 \mathrm{~mL}$ of the obtained solution was transferred to the $10 \mathrm{~mL}$ of tubes, and adjusted the $\mathrm{pH}$ value to $6.0 \sim 7.0$ with $\mathrm{NaOH}$ solution for further study.

Dry sample. $1 \mathrm{~g}( \pm 0.01 \mathrm{~g})$ of homogenized samples were accurately weighed into the centrifuge tubes with the volume of $50 \mathrm{~mL}$, then $5 \mathrm{~mL}$ of ultrapure water was added into the tubes, which kept for $2 \mathrm{~h}$ to ensure that the dry samples absorb water adequately. $15 \mathrm{~mL}$ of $10 \%$ (wt \%) TCA solution was added into the tubes. The samples were shaken vigorously on the vortex oscillators, extracted for $2 \mathrm{~h}$ at room temperature, centrifuged at $10000 \mathrm{r} / \mathrm{min}$ for $5 \mathrm{~min}$. The supernatant was transferred into $25 \mathrm{~mL}$ of colorimetric tubes. Fix the volume to scale using $10 \%$ (wt \%) TCA solution and mixed the system adequately, $5 \mathrm{~mL}$ of the obtained solution was transfer to the $10 \mathrm{~mL}$ of tubes, and adjusted the $\mathrm{pH}$ value to 6.0 7.0 with $\mathrm{NaOH}$ solution for further study.

\subsection{The calibration curve.}

A series of the Glu reserve solutions were prepared with the concentration of $0.0,100.0,200.0,300.0,400.0$, $600.0,800.0,1000.0 \mu \mathrm{g} / \mathrm{mL}$, respectively. Accurately transfer $1.0 \mathrm{ml}$ of Glu standard solutions into the $25 \mathrm{~mL}$ of the colorimetric tubes. $1.0 \mathrm{~mL}$ of phosphoric acid buffer solution with the $\mathrm{pH}$ of 6.0 and $1.0 \mathrm{~mL}$ of $2 \%$ (wt \%) ninhydrin solution were successively added into the tubes. The stock solutions were mixed uniformity and reacted at $90{ }^{\circ} \mathrm{C}$ for $15 \mathrm{~min}$. Ultrapure water was used to fix the system volume to $25 \mathrm{~mL}$ before thoroughly mixing. The ultimate concentration of standard working solutions was 0.0, 4.0, 8.0, 12.0, 16.0, $24.0,32.0, \quad 40.0 \mu \mathrm{g} / \mathrm{mL}$, respectively. Taking the absorbance intensities of the calibration solutions as the vertical and the concentration of calibration solutions as the horizontal to draw the calibration curve.

\subsection{Determination.}

$0.2 \mathrm{~mL}$ of the extraction (the volume can be adjusted appropriately according to the content of free amino acids in the samples) was accurately added into the 25 $\mathrm{mL}$ of the colorimetric tubes, $0.8 \mathrm{~mL}$ of ultrapure water, $1.0 \mathrm{~mL}$ of phosphoric acid buffer solution with the $\mathrm{pH}$ of 6.0 and $1.0 \mathrm{~mL}$ of $2 \%$ (wt \%) ninhydrin solution were successively added into the tubes. The stock solutions were mixed uniformity and reacted at $90{ }^{\circ} \mathrm{C}$ for $15 \mathrm{~min}$. Ultrapure water was used to fix the system volume to 25 $\mathrm{mL}$ before thoroughly mixing. Finally, the absorbance intensities of the solutions were measured at $570 \mathrm{~nm}$ with $1.0 \mathrm{~cm}$ cuvette with the reagent blank as reference.

\subsection{Calculation formula.}

According to the calibration curve, the content of total free amino acids in the actual samples $(\mathrm{mg} / \mathrm{kg})$ were calculated as follows: $\mathrm{X}=(\mathrm{C} \times \mathrm{V} \times \mathrm{f}) / 1000 \mathrm{~m}$

In the formula (1), X, C, V, f and m denoted the content of total free amino acids in the sample $(\mathrm{g} / \mathrm{kg})$, the concentration of total free amino acids $(\mu \mathrm{g} / \mathrm{mL})$ calculated from the calibration curve, the constant volume $(\mathrm{mL})$ after the chromogenic reaction, the diluted factor of the samples (involving the volume of the extraction solution, the volume of the test solution, and the diluted times), and the weight of the aquatic product (g), respectively.

\section{Results and discussion}

\subsection{Optimum the reaction conditions}

Scheme 1 showed the schematic illustration of the chromogenic reaction. As illustrated in scheme 1 , free amino acids and ninhydrin reacted to $\mathrm{NH}_{3}, \mathrm{CO}_{2}, \mathrm{RCHO}$ 
and reductive ninhydrin, then $\mathrm{NH}_{3}$, reductive ninhydrin and another ninhydrin condensed to the blue or purple product. A series of the Glu standard solutions varying the concentration from $0.0 \mu \mathrm{g} / \mathrm{mL}$ to $10.0 \mu \mathrm{g} / \mathrm{mL}$ reacted with ninhydrin solution in the chromogenic reaction, and the obtained UV-vis absorption spectra (Figure 1A) evidenced two distinct absorbance peaks at $400 \mathrm{~nm}$ and $570 \mathrm{~nm}$, which were attributed to the $\pi-\pi$ band of the benzene ring and the $\mathrm{N}=\mathrm{C}$ band of the reaction products, respectively [29]. For the characteristic absorption peak of the products, $570 \mathrm{~nm}$ was adopted as the determination wavelength in this work.

To get the best chromogenic effects, we optimized the reaction conditions. Figure 1B described the influence of the measurement time after the chromogenic reaction completion. As shown in Figure $1 \mathrm{~B}$ (a), the absorbance of the Glu standard solution with the concentration of $12.0 \mu \mathrm{g} / \mathrm{mL}$ was slightly higher at 15 min than that of other times. The trend of the 16.0 $\mu \mathrm{g} / \mathrm{mL}$ (Figure 1B (b)) was consistent with that of 12.0 $\mu \mathrm{g} / \mathrm{mL}$. Meanwhile, the reaction solutions appeared uniform and transparent, which indicated the favourable stability of the products. Therefore, 15 min was chosen as the measurement time after the chromogenic reaction accomplished.

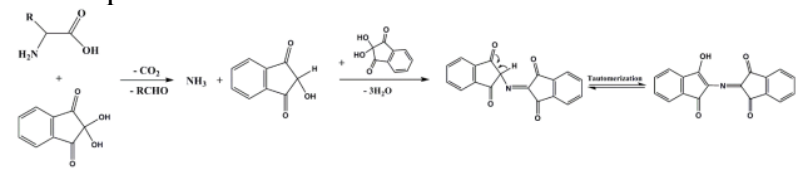

Sheme1. Schematic illustration of the chromogenic reaction.

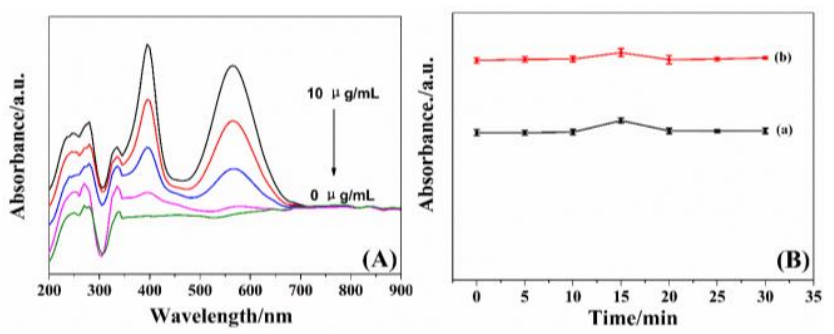

Fig. 1. (A) The absorbance spectrum of the various Glu concentrations ranging from $0.0 \mu \mathrm{g} / \mathrm{mL}$ to $10.0 \mu \mathrm{g} / \mathrm{mL}$. (Green line: $0.0 \mu \mathrm{g} / \mathrm{mL}$, peak line: $4.0 \mu \mathrm{g} / \mathrm{mL}$, blue line: 6.0 $\mu \mathrm{g} / \mathrm{mL}$, red line: $8.0 \mu \mathrm{g} / \mathrm{mL}$, and black line: $10.0 \mu \mathrm{g} / \mathrm{mL}$, respectively.) (B) The determination of measurement time at different Glu concentration. (a) $12.0 \quad \mu \mathrm{g} / \mathrm{mL}$; (b) 16.0 $\mu \mathrm{g} / \mathrm{mL}$.

Figure 2(A) showed the variation of the absorbance with different Glu concentrations under different temperatures at the same other conditions in chromogenic reaction. The results showed that the absorbance and the reaction phenomena depended on the reaction temperature. As described in figure 2 (A), the absorbance gradually accumulated with the chromogenic reaction temperature increasing from $70{ }^{\circ} \mathrm{C}$ to $90{ }^{\circ} \mathrm{C}$. Meanwhile, the reaction solutions appeared uniform and transparent. However, as the temperature continued to rise, the absorbance decreased and the reaction solutions presented precipitate. So, $90{ }^{\circ} \mathrm{C}$ was utilized as the chromogenic reaction temperature in this work. Figure
2(B) exhibited the changes of the absorbance with different Glu concentrations under different times at the same other conditions in the chromogenic reaction. As demonstrated in figure $2 \mathrm{~B}(\mathrm{a})$, the absorbance at the Glu concentration of $12.0 \mu \mathrm{g} / \mathrm{mL}$ gradually accumulated with the chromogenic reaction time increasing from $5 \mathrm{~min}$ to $15 \mathrm{~min}$. However, the absorbance lightly decreased as the reaction times continued to increase. The trends of the $16.0 \mu \mathrm{g} / \mathrm{mL}$ (Figure 2B (b)) and $20.0 \mu \mathrm{g} / \mathrm{mL}$ (Figure 2B (c)) were consistent with that of $12.0 \mu \mathrm{g} / \mathrm{mL}$, which indicated that the chromogenic reaction finished after 15 min. Therefore, $15 \mathrm{~min}$ was chosen as the chromogenic reaction time in this work.

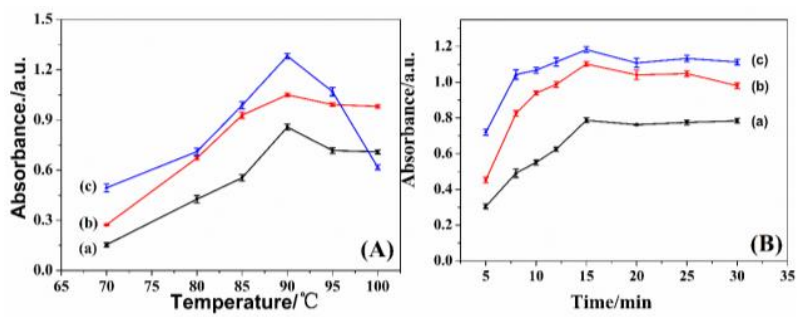

Fig. 2. The variation of the absorbance in chromogenic reaction with different Glu concentrations under different temperatures(A) and different times(B). (a) $12.0 \mu \mathrm{g} / \mathrm{mL}$, (b) $16.0 \mu \mathrm{g} / \mathrm{mL}$, (c) $20.0 \mu \mathrm{g} / \mathrm{mL}$, respectively.

Figure 3 demonstrated the effects of the solvents on the absorbance of the Glu standard solutions. The $\mathrm{H}_{2} \mathrm{O}$, acids and base were adopted in our work. As described in figure 3, the absorbance of the Glu standard solutions in $\mathrm{H}_{2} \mathrm{O}$ (Figure 3(a)) was lowest among the all solvents. As $\mathrm{NaOH}$ the solvent (Figure 3(b)), the absorbance of the Glu standard solutions slightly increased firstly, but decreased sharply at high concentration of Glu standard solutions. The absorbance of the Glu standard solutions in TCA (Figure 3(d) H3PO4 (Figure 3(e) were better than that in $\mathrm{HCl}$ (Figure 3(c). However, the relationship of absorbance and Glu concentration presented the linear. Therefore, TCA was the optimum solvent.

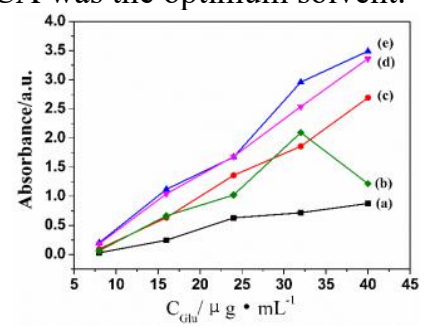

Fig. 3. The variation of the absorbance in chromogenic reaction with different Glu concentrations in various solvents. (a) $\mathrm{H}_{2} \mathrm{O}$; (b) $\mathrm{NaOH}$; (c) $\mathrm{HCl}$; (d) $\mathrm{TCA}$; (e) $\mathrm{H}_{3} \mathrm{PO}_{4}$, respectively.

\subsection{Research of the extraction reaction}

Figure 4 described the research of the extraction reaction involving the extractant (Figure 4A), the extraction time and the concentration of the extractant (i.e. TCA) (Figure 4B). The water-soluble proteins with UV absorption ability were also dissolved in the supernatant when water was used as the extraction agent. Then, the sulfosalicylic acid was needed to precipitate the protein to avoid their interference with the results. As manifested in figure 
4A(a), the absorbance of the samples using the water as the extraction agent was nearly invariant despite of extending the reaction time from $1 \mathrm{~h}$ to $8 \mathrm{~h}$. Compared with water, TCA was utilized not only as the extractant but also as the precipitator to remove the water-soluble proteins. The absorbance of the samples utilized the $20 \%$ TCA as the extraction agent gradually increased with the extraction time enlarging from $0.5 \mathrm{~h}$ to $2 \mathrm{~h}$ and decreased with the extraction time further to $3 \mathrm{~h}$ (Figure 4A(b)). Figure 4B demonstrated the effects of the extraction time and the concentration of the extractant. The results showed that the absorbance achieved the plateau after reacting $2 \mathrm{~h}$ regardless of the TCA concentration varying from $5 \%$ to $20 \%$. However, it found that the concentration was too low to remove the water-soluble proteins when $5 \%$ TCA was used, which was needed to margin the centrifugal speed or the centrifugal time to accomplish the removal of the proteins. In the meantime, the extraction effect and the facile operation of $10 \%$ were equivalent with $20 \%$, which indicated that the optimum concentration of TCA was $10 \%$.

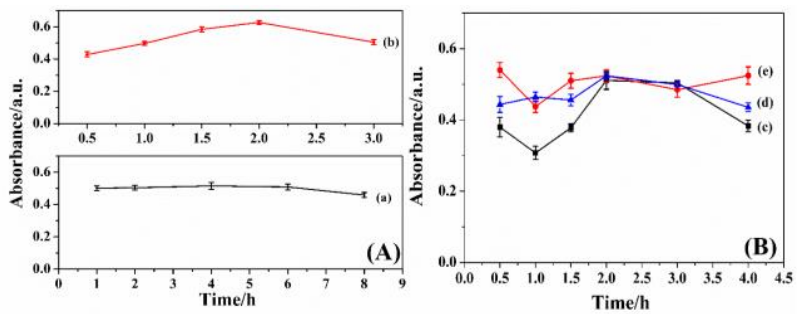

Fig. 4. Research of the extraction reaction on the extractant, the extraction time and the concentration of the extractant. (A) (a) water and (b) $20 \% \mathrm{TCA},(\mathrm{B})(\mathrm{c}) 5 \% \mathrm{TCA},(\mathrm{d}) 10 \% \mathrm{TCA}$ and (e) $20 \%$ TCA.

\subsection{Linear range, detection limit, recovery and precision of the established method}

It was performed under the optimum reaction conditions. Each sample was tested two times in parallel to ensure the reliability of the results. The detail addition standard experiments were conducted as follows. $10.0 \mathrm{~g} / \mathrm{kg}, 20.0$ $\mathrm{g} / \mathrm{kg}$ and $40.0 \mathrm{~g} / \mathrm{kg}$ of the Glu calibration solutions were respectively added to Carassius auratus auratus, which had the relative low background and acted as the blank sample. 3 samples were measured in parallel with each concentration. And the blank experiments were conducted at the same time.

The results were shown in Figure 5 and list in Table 1 and Table 2, which indicated that the obtained method exhibited good linear with the TFAA in the concentration range of $0.0 \sim 40.0 \mu \mathrm{g} / \mathrm{mL}\left(\mathrm{R}^{2}=0.9958\right)$. The average recoveries were $105.4 \% \pm 3.20 \%, 96.8 \%$ $\pm 2.81 \%$ and $97.8 \% \pm 2.40 \%$ at the low concentration (i.e. $10.0 \mathrm{~g} / \mathrm{kg}$ ), medium concentration (i.e. $20.0 \mathrm{~g} / \mathrm{kg}$ ) and high concentration (i.e. $40.0 \mathrm{~g} / \mathrm{kg}$ ) of TFAA, respectively. The precision of the method was $6.14 \%$, which was calculated by the eleven times results of the blank samples (i.e. the Roast Ophiocephalus argus) in parallel. The limit of detection (LOD) is $1.96 \mu \mathrm{g} / \mathrm{mL}$ $(\mathrm{S} / \mathrm{N}=3)$. The results suggested that the method established in our work presented the good accuracy and the favorable precision, which manifested that it could be applied to detect the TFAA in real samples.

\subsection{Detection of TFAA in real samples}

Figure 6 displayed the results of TFAA detected by the established method in various aquatic products. According to the data in the figure 6 , all the collected samples contained the TFAA, which depended on the varieties of the aquatic products. For instance, the TFAA in $S$. nudus achieved to $138.14 \mathrm{~g} / \mathrm{kg}$, which was consistent with the reported value of $103 \mathrm{~g} / \mathrm{kg}$ measured by automatic amino acid analyser method [30], further verified the accuracy and reliability of the present method in our work. Furthermore, the TFAA in S. nudus was higher than the other collected samples, which indicated the $S$. nudus featured the wonderful nutritional value. Meanwhile, the content of TFAA in shrimp and crabs were higher than that in fish, which may be one reason why shrimp and crabs taste well than fish, and the results were consistent with the literatures [19,31].

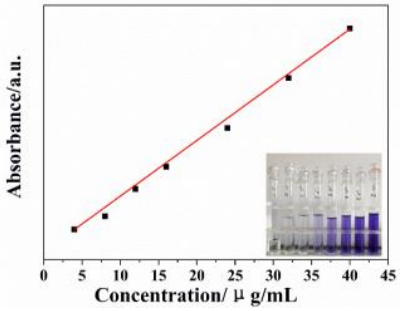

Fig. 5. The relationship between the absorbance and the various Glu concentrations. Inset: Photographs captured with various Glu concentrations.

Tab. 1 The calibration equation, linear range, precision, and LOD of the established method.

\begin{tabular}{cccccc}
\hline $\begin{array}{c}\text { Analys } \\
\text { es }\end{array}$ & $\begin{array}{c}\text { Linear } \\
\text { range/ } \\
\boldsymbol{\mu g} \cdot \mathbf{m L}^{-1}\end{array}$ & $\begin{array}{c}\text { The } \\
\text { calibration } \\
\text { equation }\end{array}$ & $\mathbf{R}^{\mathbf{2}}$ & $\begin{array}{c}\text { Precision } \\
/ \%\end{array}$ & $\begin{array}{c}\mathbf{L O D} \\
/ \boldsymbol{\mu g} \cdot \mathbf{m L}^{-1}\end{array}$ \\
\hline TFAA & $0.0 \sim$ & $\begin{array}{c}\mathrm{y}= \\
-0.45967+ \\
0.09387 \mathrm{x}\end{array}$ & 0.9958 & 6.14 & 1.96 \\
\hline
\end{tabular}

Tab. 2 The recoveries of the established method.

\begin{tabular}{ccccc}
\hline $\begin{array}{c}\text { Spiked/g. } \\
\mathbf{k g}^{-1}\end{array}$ & $\begin{array}{c}\text { Measured//g. } \\
\mathbf{k g}^{-\mathbf{1}}\end{array}$ & $\begin{array}{c}\text { Recoveries/ } \\
\mathbf{\%}\end{array}$ & $\begin{array}{c}\text { Average } \\
\text { recoveries/ } \\
\mathbf{\%}\end{array}$ & $\begin{array}{c}\text { Precision/ } \\
\mathbf{\%}\end{array}$ \\
\hline \multirow{2}{*}{$\mathbf{1 0}$} & 10.6 & 105.6 & & \\
& 10.9 & 108.6 & 105.4 & 3.20 \\
\hline \multirow{2}{*}{$\mathbf{2 0}$} & 10.2 & 102.0 & & \\
& 19.4 & 96.8 & & 2.81 \\
\hline \multirow{4}{*}{$\mathbf{4 0}$} & 18.8 & 94.0 & 96.8 & \\
& 19.9 & 99.6 & & 2.40 \\
\hline
\end{tabular}




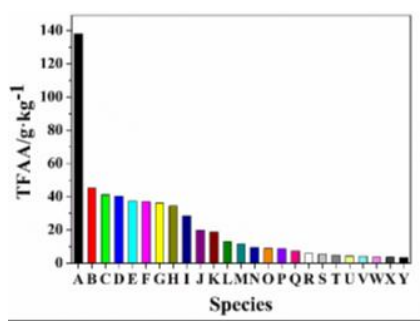

Fig. 6 The TFAA detected by the established method in different aquatic products. (A: Sipunculus nudus, B: freshwater shrimps, C: Penaeus monodon, D: Procambarus clarkii, E: Procambarus clarkii, F: Eriocheir sinensis, G: Portunus trituberculatus, H: Sinonovacula constricta, I:

Macrobranchium nipponense, J: Paphia undulata, K: Fried metapenaeusensis, L: Fried Penaeus vannamei, M: Venerupis variegata, N: Roast Loligo chinensis, O: Roast Cololabis saira, P: Roast Carassius aumtus, Q: Roast Ophiocephalus argus, R:

Cyprinus carpio, S: Ophiocephalus argus, T: Parabramis pekinensis, U: Carassius aumtus, V: Lateolabrax japonicus, W:

Pseudosciaena crocea, X: Siniperca chuatsi, Y: Ostrea rivularis, respectively.)

\section{Conclusion}

In summary, we developed the determination method of total free amino acid in Sipunculus nudus and other various aquatic products based on UV spectrophotometry. The obtained method revealed a good linearity in the TFAA range $0.0 \sim 40.0 \mu \mathrm{g} / \mathrm{mL}\left(\mathrm{R}^{2}=\right.$ 0.9958 ) with the limit of detection (LOD) $1.96 \mu \mathrm{g} / \mathrm{mL}$, the precision of $6.14 \%$ and the addition standard recoveries of $95.1 \% \sim 108.6 \%$. Finally, the established method was applied in detection of the TFAA in the aquatic products involving the fish, the shellfish, the crustaceans and the cephalopods. The results demonstrated that the TFAA distinguished between shrimp, crabs and fish. Furthermore, the TFAA in Sipunculus nudus was as high as $138.14 \mathrm{~g} / \mathrm{kg}$ and higher than the other collected aquatic products, which indicated that the Sipunculus nudus featured the wonderful nutritional value.

\section{Acknowledgments}

This work was financially supported by the central public-interest scientific institution basal research fund (East China Sea Fisheries Research Institute) (2019T12) and the special research fund for the national non-profit institutes (East China Sea Fisheries Research Institute) (2014T14).

\section{References}

1. Li, J.W., Zhu, C.B., Guo, Y.J., Xie, X.Y., Huang, G.Q., \& Chen, S.W. Aquaculture, 437, 175-181 (2015).

2. Yang, C., Zhang, J., Zhong, R., Guo, Z., Wang, Q., \& Zheng, Z. Aquacul. Rep. 16, 100271(2020).

3. Zhang, G.H., Li, L., Zhao, M.M., \& Wu, G.H. Acta Nutr. Sin. 30, 318-320(2008).
4. Zhu, Y.L., Li, S.D., Zhou, J.L., \& Jiang, M. Chem. World, 53, 269-271 (2012).

5. Dong, L.F., Zhang, Q., Tong, T., Xu, M.Z., \& Chen, J.H. South China Fish. Sci., 8, 60-65(2012).

6. Jiang, D.W., Sheng, X.R., Jia, F.X., Cu, Z.Y., \& Li, S.L. Chinese J. Biochem. Pharm., 25, 96-97(2004).

7. Shen, X.R., Jiang, D.W., Jia, F.X., \& Chen, M.H. Chinese J. Mar. Drugs. 23, 30-32(2004).

8. Xia, Q.F., Tan, H.L., Qin, X., \& Qian, S.J. China Trop Med. 7, 2192-219 (2007)3.

9. Chen, X.X., Lin, X.Y., Lu, C.Y., \& Ye, Y. Mar. Sci. 32, 66-70(2008).

10. Adrianov, A.V., \& Maiorova, A.S. Russ. J. Mar. Biol. 36, 1-15(2010).

11. Liu, T., Wu, H., Zha, C.Y., Xie, J., \& Lin, Y. Food Ind. 29, 71-74 (2012).

12. Cappello, T., Giannetto, A., Parrino, V., Maisano, M., Oliva, S., Marcoet, G.D., Guerriero, G., Mauceri, A., \& Fasulo, S. Comp. Biochem. and Physiol. D. 26, 32-39 (2018).

13. Castillo, S., \& GatlinIII, D.M. Aquaculture 497, 17-23(2018).

14. Liang, Y., Lu, J., Zhang, L., Wu, S., \& Wu, Y. Food Chem. 80, 283-290(2003).

15. Alasalvar, C., Topal, B., Serpen, A., Bahar, B., Pelvan, E., \& Gökmen, V. J. Agri. Food Chem. 60, 323-6332(2012).

16. Huang, Y., Wang, T., Fillet, M., Crommen, J., \& Jiang, Z. J. Pharm. Anal. 9, 254-258 (2019)

17. Deng, J.C., Wang, X.C., \& Liu, Y. Sci. Technol. Food Ind. 32, 106-108(2010).

18. Zhang, L.H., Cai, J.W., Zhou, K., Ma, C.Y., Feng, Y.B., Bi, H.Y., Gao, H., \& Li, J.R. J. Food Saf. Qual. 6, 3621-3626(2015).

19. Zhang, S.P., Qiu, W.Q., Lu, Q., \& Chen, S.S. Food sci. 38, 170-176(2017).

20. Wang, H.L., Shi, W.Z., Qiu, W.Q., \& Wang, X.C. Prog. Fish. Sci. 39, 97-105. (2018)

21. Sun, C.F., Zhou, N., Zhu, L., Ma, C., Yang, J.R., \& Zhang, J.M. Mod. Food Sci. Technol. 32, 200-206. (2016)

22. Li, Y., Xie, Y., \& Yang, F.H. Hubei Agric. Sci. 57 79-83. (2018)

23. Ye, H.L., Tian, L.L., Cai, Y.Q. Huang, D.M. Shen, Z.D., \& Shi, Y.F. Earth Environ. Sci. 474, 052050(2020)

24. Zhao, R., Cui, J., Mei, L.R., Xu, X.J., Jin, Y., Yan, S.J., \& Liu, X. Food Res. Dev. 38, 156-160(2017).

25. Halil, I.U. J. AOAC Int. 97, 238-244 (2014).

26. Zhang, Y.F., Zhang, Q., Wang, R.M., \& Zhang, H.C. Seed, 33, 111-114. (2014)

27. Ye, H.L., Tian, L.L., Shi, Y.F., Yu, H.J., Cai, Y.Q., Xi, Y.F., Tang, Y.Y., Zhang, Z.Q., \& Huang, D.M. Earth Environ. Sci. 474, 052029(2020)

28. Li, S.R., Wang, L., Tang, X.M., Wang, H.H., Liu, X.F., Jia, H.L., \& Pan, Y. Food Sci. Technol. 42, 281-284. (2017)

29. Jabeen, S., Alam, S., Saleem, M., Ahmad, W., Bibi, R., Hamid, F.S., \& Shah, H.U. Arabian J. Chem. 12, 2411-2417. (2019)

30. Zhang, C.H., Takeshi, S., \& Yumiko, Y. J. Zhanjiang Ocean Univ. 20, 24-27. (2000) 
31. Chen, D.W., Su, J., Liu, X.L., Yan, D.M., Lin, Y., Jiang, W.M., \& Chen, X.H. J. Aquat. Food Prod. Technol. 21, 369-379(2012). 